\title{
Da Educação à Intervenção Social: a construção do conhecimento na
}

\author{
transformação da realidade
}

\section{From Education to Social Intervention: the construction of knowledge in the transformation of reality}

\author{
Ricardo Cardoso, Darlinda Moreira \\ Universidade Aberta
}

\begin{abstract}
Resumo
Este artigo aborda as potencialidades que as ações educativas, enformadas num projeto de intervenção social, podem ter para a transformação da realidade de indivíduos que se encontram numa situação de vulnerabilidade. Através de duas experiências educativas construiu-se, numa linha metodológica de investigação-ação participativa, um projeto de educação e intervenção social que permitiu simultaneamente conhecer, planificar, transformar, observar e refletir sobre o aumento da consciência crítica e autonomia de seis mulheres. $\mathrm{O}$ ato de educar ganhou uma outra dimensão, quando, através de um projeto de intervenção, devidamente participado, se readaptou o conhecimento à prática a fim de a transformar e melhorar.

Palavras-Chave: educação, intervenção social, projeto; adultos; investigação participativa.
\end{abstract}

\begin{abstract}
This article discusses the potential that educational actions shaped in a project of social intervention, may have to transform the reality of individuals who are in a vulnerable situation. Throughout two educational experiences it was built a project of education and social intervention, that simultaneously helped identify, plan, process, observe and reflect on the increase of critical awareness and autonomy of six women. The methodological approach was of participatory action research. The act of educating gained another dimension when, through an intervention project, properly participated, knowledge was reconfigured to practice in order to better transform and improve.

Keywords: education, social intervention, project; adults; Participatory research.
\end{abstract}

Este artigo apresenta parte de um estudo mais amplo, realizado no âmbito de um curso de doutoramento em Educação e Interculturalidade, onde se realçam as relações entre a educação e a intervenção social e respetivas potencialidades para a orientação e agregação de projetos de intervenção social. Nesta relação que aprofundamos neste artigo, a educação estabelece a ligação do conhecimento específico do universo da pedagogia, enquanto a intervenção social emprega a experiência da ação no terreno do trabalho social.
A potencialidade que as ações educativas, enformadas em projetos de intervenção social devidamente construídos e desenhados podem ter para a transformação da realidade, é uma das abordagens que aqui apresentamos, salientando o papel da educação e da intervenção social no contínuo melhoramento das ações que promovem a resolução de problemas e a inclusão da diferença.

A mudança a que se aspira, através da planificação de ações concretas, a realizar num grupo de 6 mulheres, com idades compreendidas entre os 53 e os 72 anos, utentes de uma Instituição Particular de Solidariedade Social (IPSS), no norte de Portugal, insere-se, num ambiente em que as participantes se caraterizam por estarem numa situação de fragilidade biopsicossocial.

Neste quadro, o ato de educar ganha uma outra dimensão, quando, de forma rigorosa se reflete; se toma consciência das múltiplas necessidades existentes e das situações problemáticas; se apresenta uma solução viável para um problema concreto; se elabora um plano de intervenção o mais completo possível, sistemático, ou seja, científico; se readapta o conhecimento à prática a fim de a transformar e melhorar.

A partir daqui o caminho previamente negociado com as participantes, segue uma direção acordada por todos e que contribui para o empoderamento e aumento da consciência crítica tendo como fim a resolução de problemas situacionais individuais e do grupo. $\mathrm{O}$ educador, aqui também investigador, promove espaços democráticos onde as participantes têm oportunidade de se autorrecriar, reconstruindo a sua história, reinventando-a.

As potencialidades das ações educativas na promoção do bem-estar de pessoas vulneráveis

Estamos a viver uma época impregnada de novos acontecimentos políticos, económicos e sociais. A globalização e urbanização crescentes têm vindo a fragilizar as estruturas comunitárias tradicionais, promovendo novas formas de organização da vida dos indivíduos com todos os benefícios e aspetos negativos que isto pode acarretar. 
A potencialidade das ações educativas na promoção do bem-estar de pessoas vulneráveis advém da necessidade de minimizar os resultados nefastos que a sociedade de hoje nos impõe. Se por um lado todos ganhamos com as inúmeras possibilidades da livre circulação de informação e da democratização do acesso a bens e serviços, por outro, perdemos devido ao "alastramento aparentemente contraditório da solidão psicológica e social que impôs dramas pessoais inéditos: o abandono material e afetivo dos velhos e a indiferença objetiva" face às necessidades de acompanhamento das crianças e dos jovens, que a aceleração da nova cadência de vida "pretende justificar, são, entre outras, emergências contundentes das disfunções sociais existentes" (Carvalho \& Baptista, 2004 p. 24).

Em nome do individualismo, os sujeitos encontram-se em constante risco, sendo a sua vulnerabilidade "vista, numa lógica de mercado, como uma vantagem competitiva", pois a constante proliferação do discurso do individualismo e das práticas neoliberais nas sociedades contemporâneas têm vindo "a exacerbar as injustiças sociais e, consequentemente, a condicionar a cidadania e o seu exercício". (Vieira, 2015 p.12)

Consideramos a educação como um dos principais "motores" que favorecem o desenvolvimento humano, cultural e socioeconómico de um país. Possui um papel decisivo no desenvolvimento da sociedade e, em geral, através dela, se conquista a participação de todos os seus indivíduos. Compreendemos assim a educação como fator decisivo na construção de uma sociedade mais justa e igualitária, capaz de promover uma sustentabilidade económica e, acima de tudo, promotora do bem-estar social global.

Estamos de acordo com Amado (2013) quando refere que é à educação que compete trabalhar pela realização da dimensão que assume a conceção do ser humano como ser livre, não formatado, independente, cooperante, sendo responsável pelo seu futuro, enquanto membro de um grupo e de uma comunidade. É, portanto, através da Educação que se pode libertar o homem de determinismos e da pressão a que é sujeito.

Nestes prossupostos, a educação que abordamos nesta investigação é orientada para o adulto. Sousa (2008) refere que ser adulto, enquanto categoria social, é entender que esta fase da vida implica especificidades, problemas e características próprias que devem ser objeto de atenção de estudo e de intervenção política e social. Esta autora refere também que o estádio de "adulto" não é estanque, mas algo que está em constante mudança de acordo com o seu contexto social e histórico.

A educação de adultos é um conjunto de teorias "estratégias, orientações e modelos organizacionais com o objetivo de interpretar, dirigir e administrar os processos de instrução individuais e colectivos ao longo de toda a vida." (Federighi e Melo 1999 p. 14)

Neste estudo e contexto específico, educação de adultos é um processo formativo de caráter informal que vai acontecendo ao longo da vida e que vai para além dos sistemas de ensino e de formação profissional tradicionais, pois projeta-se na realização dos indivíduos, uma vez que a educação promove, intencionalmente, não apenas o desenvolvimento individual de cada sujeito participante, mas também social e cultural, no sentido em que oferece a cada ser humano, um "património comum (espiritual, material e de competências várias), que vale a pena ser transmitido e, ao mesmo tempo, o prepara para exercer sobre esse património uma constante adaptação, renovação e enriquecimento" (Amado, 2013 p.22).

\section{Educar para construir e transformar a realidade}

O papel da educação no processo de mudança social remete-nos, obrigatoriamente, para a questão de qual o papel da educação nas funções da sociedade. Na ação educativa, existem, tal como refere Tedesco (1995), duas posições extremas, ou pelo menos possíveis. Uma delas diz respeito à função reprodutora que a educação tem na ordem social, e a outra refere-se à possibilidade de promover mudança e progresso nos indivíduos e nas sociedades

A necessidade de repensarmos seriamente o mundo atual, remete-nos para uma discussão sobre a importância de humanizarmos o mundo, através da forma como educamos e praticamos a educação, sobre de que forma abordamos as relações humanas no dia-a-dia. "A afirmação histórica do ser humano como ser esperançoso e em busca de liberdade é a base para a construção da visão ética e política indispensável ao projeto que promove nos sujeitos a sua transformação e a dos outros e a emancipação do "paradigma emancipatório da sociedade" (Zitkoski, 2006 p. 17).

As questões que se relacionam com os altos níveis de desemprego e do emprego precário, lançam muitos indivíduos para situações de pobreza irremediáveis, colocando-os em situação de exclusão social e de outros problemas que vão experimentando, devido à situação pela qual irrompem, levando-os, muitas vezes, ao flagelo da toxicodependência e da proliferação dos sem-abrigo e dos sem-papéis. Desta crise, são forçados um sem número de indivíduos a emigrar, que em difíceis condições, aumentam o jogo exógeno e endógeno das exclusões e reforçam os comportamentos xenófobos e autoritários que existem nos países de destino.

A educação que temos como intenção é aquela que parte do princípio que a natureza humana não é determinada por estruturas ou princípios inatos. Interessa-nos conhecer as pessoas e os contextos sociais e culturais onde se encontram para melhor atuar na emancipação sociocultural e pela ação

Procuremos então entender em que se apoia o estabelecimento de uma relação educativa no contexto da intervenção social. Recorremos a Capul e Lemay, (2003), que na obra «Da Educação à Intervenção Social», referem a função de acompanhamento; a função avaliativa; a função de modificação de comportamento; e a função de mediador como condições para que se estabeleça o desenvolvimento da relação segundo as funções do educador:

* A função de acompanhamento - o acompanhamento por parte do educador, que é de facto um mediador entre o(s) sujeito(s) e o seu meio ambiente, tenta, respeitando e 
auscultando o outro e sabendo que deve impor limites, estar presente o suficiente, ser útil, tornar-se significativo e suficientemente afastado para que não imponha a sua direção por excesso de presença e de imposição.

* A função avaliativa - o educador tem a função avaliativa, ultrapassando em muito o aspeto relacional. Só a partir de uma escuta atenta, de uma observação sistémica de tudo o que foi trabalhado é que se podem apreciar as aptidões e os limites de um participante. Só assim será possível propor um campo, um possível caminho, tendo em vista o desenvolvimento do sujeito assente na avaliação realizada.

* A função de modificação de comportamento - também em educação existe a possibilidade de modificação, não sendo apenas campo das áreas de intervenção como a medicina e a psicologia. A aprendizagem de determinadas condutas, novas formas de estar e ser, a aquisição de novas competências do saber-estar, saber-fazer e saber-ser parecem ter acoplados em si uma função que modifica o comportamento dos sujeitos.

* A função de mediador - ser-se mediador é literalmente pôr-se no meio. O educador é sempre o sujeito que no estabelecimento de uma ponte entre um sujeito atual e o que aspira aprender, promove o seu processo de evolução. É também aquele que pressente a ausência de palavras, num processo qualquer de mediação e que garante, pela sua própria presença, que um espaço de paz e de busca constante de soluções possa ser construído, sempre com o objetivo que permita aos protagonistas participar no espaço nem muito vazio, nem muito obstruído

\section{A construção de projetos de educação e intervenção social}

Colocamos a intervenção social que promovemos neste trabalho exatamente aqui: entre a necessidade de responder aos problemas dos indivíduos, promovendo, através de ações, o seu bem-estar, e na necessidade, com esta atitude, de promover o conhecimento da ação por si, num processo que investiga enquanto age e que aceita o ator social como preponderante no processo.

$\mathrm{Na}$ prática, qualquer processo de intervenção social deverá ter alocado um projeto de intervenção. $\mathrm{O}$ diagnóstico, a planificação, a aplicação/execução e a avaliação fazem parte de um conjunto de ações que levam a intervenção social a um patamar de qualidade desejado.

Adotamos a estrutura das fases da elaboração de um projeto, ver figura 2, de Serrano (2008), que nos explicita cada passo a tomar:

$\checkmark$ Diagnóstico - é a fase que implica que reconheçamos a situação em si, o problema em questão. Aqui deverá o interventor social ter o cuidado de examinar, auscultar a realidade a estudar: as pessoas, o meio envolvente as circunstâncias e caraterísticas que poderão influenciar diretamente o projeto. É necessário que o interventor social possa elucidar todos os envolvidos no processo dos problemas que detetaram. É nesta fase inicial que se pode detetar os principais problemas de determinada realidade. O grande objetivo do diagnóstico é o conhecimento da realidade, daí ser uma fase de vital importância para a elaboração do projeto. É nesta fase que deverão ser detetadas as necessidades, que se estabelecem as prioridades, se fundamenta o projeto, delimita o problema, localiza a realização do projeto, assim como se define a sua área de intervenção, se revê o estado de arte e se faz uma previsão quer da população, quer dos recursos;

$\checkmark$ Planificação - surge após a consciencialização do diagnóstico, entretanto já realizado, e serve, essencialmente, para determinar o que se deve fazer, introduzir organização e racionalidade à ação que se pretende promover. É nesta fase que são traçados planos para a execução do projeto e tem como principais objetivos determinar os resultados que se pretendem obter; elaborar as normas de atuação de cada um dos intervenientes; prever as situações possíveis e preparar estratégias corretivas, ou seja, a planificação consiste em antecipar, tentando vislumbrar o que se poderá desenrolar no futuro. É nesta fase que deverão ser definidos os objetivos gerais e específicos, qual a metodologia a adotar, as ações, as atividades as técnicas e instrumentos, definir uma calendarização, assim como quais os recursos materiais e humanos disponíveis;

$\checkmark$ Aplicação/Execução - esta é a fase em que se põe em prática o projeto e em que se acompanha controladamente o mesmo. É a fase prática do processo de intervenção social.

$\checkmark$ Avaliação - aqui, chegados, tentaremos responder à pergunta: o que conseguimos? Esta é uma etapa, acima de tudo, de reflexão, e será aqui onde serão avaliados os resultados das ações que se realizaram na execução do projeto de intervenção social. Ao contrário da avaliação que nasceu de uma tradição positivista na investigação educativa, aqui, a avaliação existe para melhorar, ou seja, a avaliação não é um fim, mas sim um meio para melhorar sistematicamente a ação social e para se fazer um uso mais adequado dos recursos disponíveis. Os passos para que a avaliação se dê efetivamente têm que passar por uma avaliação do diagnóstico, ou seja, se a questão/problema inicialmente levantada é a mais correta. Passa também por uma avaliação do processo que analisa se o 
caminho percorrido para solucionar determinado (s) problema (s) foi o mais correto tendo em vista os objetivos definidos. Por fim, a avaliação final, que é caraterizada por uma avaliação de todos os elementos que proporcionaram a execução do projeto em si.

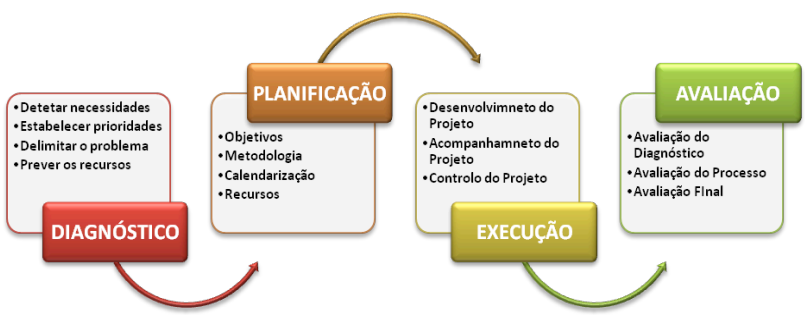

Figura 1 - Passos para a planificação de um projeto

\section{Metodologia}

\section{A Investigação-Ação Participativa}

A metodologia adoptada na investigação realizada foi a Investigação-Ação Participativa. $\mathrm{Na}$ sua execução foram usados um conjunto de métodos e técnicas específicos que foram fulcrais para a dinâmica que se pretendeu criar com as duas experiências educativas.

Neste artigo destacamos apenas a importância da elaboração de projetos de intervenção social, onde a planificação de um conjunto de atividades, enformadas em duas experiências educativas, resultou numa forma concreta, estruturada e devidamente executada, de se promover a participação dos sujeitos num conjunto de ações para a resolução de alguns dos seus problemas.

A realidade concreta que se experienciou, permitiu-nos, através de conversas intencionais, indagar os utentes da instituição, de forma a perceber o seu interesse em participar numa experiência educativa. Desta abordagem, seis mulheres aceitaram participar, tendo o investigador explicitado todo o projeto $\mathrm{e}$ destacado o âmbito participativo da metodologia e, que apesar de ter um projeto desenhado previamente, iria adaptar-se às necessidades e problemas que pudessem emergir dos primeiros contactos, pretendendo aumentar algumas competências por forma que as participantes melhor fizessem face às suas necessidades e problemas.

Com um total de sete participantes, incluído agora o investigador, e dado que se tratava de um projeto educacional, a técnica escolhida foi o grupo de discussão, pois consiste numa forma aberta e livre de participação permitindo às participantes expor as suas ideias, manifestar os seus anseios, alegrias, etc. Desta primeira abordagem, e de uma primeira experiência educativa que contemplou 10 sessões, com cerca de $2 \mathrm{~h}$ cada, no formato de grupo de discussão, onde se privilegiou a partilha de narrativas e histórias de vida e exercícios de dinâmica de grupo, visionamento de filmes e leitura de jornais trabalhou, aquilo que priorizou, pelo nível de importância e também pela capacidade de resposta, através de um desenho de projeto (Cardoso \& Moreira, 2015).

O processo teve continuidade, havendo a necessidade de compreender se, passado meio ano, a primeira experiência educativa tinha correspondido às necessidades iniciais.

Desta primeira avaliação surgiram outros problemas e novas necessidades, que conduziram à segunda experiência educativa a qual surge com o intuito de ir ao encontro novamente de um desenho de projeto, que se renova segundo o contexto que se vai atualizando à medida que a experiência decorre. As conversas intencionais continuaram a ser realizadas, de forma a compreender o que havia representado a primeira ação daquele projeto, e de que forma um segundo conjunto de sessões poderia corresponder mais e melhor quer às expectativas das participantes, quer às suas reais necessidades e problemas.

Depois de seis meses, a segunda experiência educativa teve o seu início, onde também foram abordados temas, que através de exercícios de dinâmica de grupo, foram trabalhados de forma a combater-se determinados estereótipos, preconceitos, etc. recorrendo novamente ao visionamento de novos filmes e à leitura de novas histórias de vida. As narrativas continuavam a ser o aspeto central da investigação, pois era através delas, que o investigador conseguia compreender ainda mais o quão complexo é cada participante.

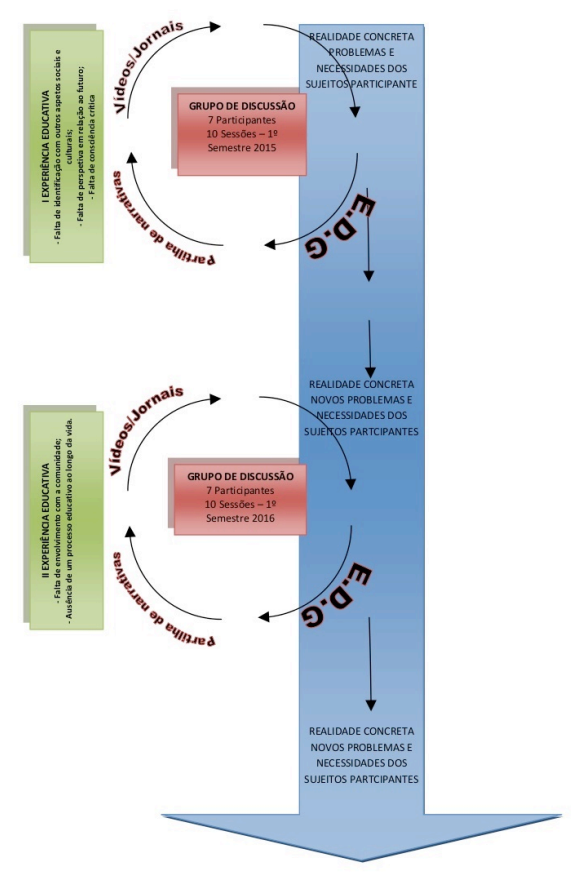

Figura 2 - Planificação metodológica

\section{Resultados}

A participação das 6 mulheres foi satisfatoriamente aumentando à medida que as sessões se iam realizando. O sentimento de estarem envolvidas no projeto, onde os objetivos eram claros, ajudou a que as participantes pudessem ter consciência de que participavam em algo concreto, devidamente desenhado e planeado e que a continuidade no mesmo era fator necessário para chegar a algum lado. Por exemplo, era frequente perguntarem:

"O que será que vamos fazer para a semana?" (Participante E, 2016) 
Ou mostrar que dominavam o processo, como mostram as palavras da Participante B

"Já estou a perceber tudo! Agora estamos a ver estes vídeos, e depois vamos partilhar o que sentimos ao vê-los. Isto tem tudo um objetivo, nada é feito em vão" (2017)

Todas as participantes mostraram interesse em participar ativamente na conceção do desenho do projeto (diagnóstico, elenco de necessidades e problemas, avaliação, etc.), como se pode ver nas seguintes afirmações:

"Acho que ao vermos filmes sobre pessoas de outras nações, vamos compreendê-las melhor! Assim é bem melhor. Prefiro saber o que vamos fazer para a semana, porque já sabemos o que esperam de nós" (Participante A, 2015)

"Prefiro assim, do que ir para a sala de atividades do lar, onde a gente não sabe se vai pintar, ou rezar o terço. Aqui a gente aprende alguma coisa e traçamos o que queremos aprender" (Participante D, 2015)

Foi através da planificação de atividades que muitos dos objetivos propostos inicialmente puderam ser atingidos: o aumento da consciência crítica das 6 mulheres; a resolução de problemas situacionais individuais e de grupo; o fortalecimento dos laços afetivos entre os elementos; o melhoramento de compreensão para a diversidade social e cultural.

A nível institucional, o desenvolvimento do projeto de intervenção, serviu, para que alguns elementos da equipa técnica da IPSS desenvolvessem mais interesse nesta forma específica de se atuar. A direção técnica da Estrutura Residencial para Idosos, do Serviço de Apoio Domiciliário e do Centro Comunitário, mostrou abertura para a implementação deste método para as mais variadas situações e utentes, pois reconheceu ser uma forma concreta e devidamente planificada de se produzir resultados específicos e mensuráveis.

\section{Considerações Finais}

A necessidade da edificação de uma sociedade mais inclusiva, apoiada numa cidadania participada, democrática e responsável, implica ter consciência de que é necessário envolver os indivíduos na resolução dos problemas de carácter individual e social. Para que a promoção do bem-estar dos sujeitos que se encontrem numa situação de vulnerabilidade social seja concretizada, é necessário que a dinamização de projetos de educação e de intervenção social assuma um maior peso na forma de se intervir junto dos indivíduos.

Apesar dos projetos de intervenção social serem desenhados especificamente para contextos únicos, eles têm a possibilidade de abraçarem novas realidades, pois são altamente flexíveis, adaptando-se à realidade em concreto, pois preveem, orientam e preparam o caminho que se vai percorrer para o seu posterior desenvolvimento.

A construção de um projeto de intervenção social, permitiu-nos, concertadamente, promover a mudança, aumentando a consciência crítica de um grupo de seis mulheres, respondendo de forma satisfatória às necessidades que cada uma apresentou individualmente e em grupo. Ao longo dos dois anos, em que este projeto de investigação e intervenção social decorreu, fomos aperfeiçoando-o, melhorando-o e adaptando-o à realidade que está em constante mudança, mas que mesmo assim, aspira ser a melhor forma de podermos intervir socialmente.

\section{Referências}

Amado, J. (2013) Manual de Investigação Qualitativa em Educação. Coimbra: Imprensa da Universidade de Coimbra.

Bisquerra, R. (2009) Metodología de la investigación educativa. Madrid: Lavel, Industria Gráfica. S.A.

Borda, F. (2009) Una Sociología sentipensante para América Latina. Colección Pensamiento Latinoamericano. Biblioteca Universitaria. Ciencias Sociales y Humanidades. Siglo del Hombre Editores.

Brandão, C. (2007) Pesquisa Participante. São Paulo: Editora Brasilense

Capul, M. \& Lemay, M. (2003). Da Educação à Intervenção Social. Porto. $2^{\mathrm{a}}$ ed. Porto Editora

Cardoso, R. \& Moreira, D. (2015) Contar histórias de vida: um processo intercultural de conscientização e de aprendizagem ao longo da vida. "Revista de Estudos e Investigação em Psicologia e Educação". ISSN 2386-7418. Vol. extr., $n^{\circ} 5$ (2015), p.69-73

Carvalho, A. \& Baptista, I. (2004) Educação Social. Fundamentos e Estratégias. Porto: Porto Editora

Federighi, P., Melo, A. (1999). Glossário de Educação de Adultos na Europa. Lisboa: Associação Europeia para a Educação de Adultos.

Freire, P. (2003). Educação e Mudança . Rio de Janeiro : Paz e Terra.

Freire, P. (1970) Pedagogia do Oprimido. São Paulo: Paz e Terra.

Freire, P. (1980). Conscientização: teoria e prática da libertação. São Paulo: Editora Moraes .

Serrano, G. P. (2008). Elaboração de Projetos Sociais. Casos Práticos. Porto: Porto.

Sousa, F. (2010). O que é ser adulto - A Sociologia da Adultez. Porto: Memória Imaterial.

Tedesco, J. (1995) Sociologia da Educação. $4^{\mathrm{a}}$ Ed. Campinas: Autores Associados.

Vieira, I. (2015) A Participação. Um paradigma para a intervenção social. Lisboa: Universidade Católica Editora.

Zitkoski, J. (2006) Paulo Freire \& a Educação pensadores \& educação Belo Horizonte, $2^{\mathrm{a}}$ Ed. Autêntica 